\title{
THE CUSTOMS UNION ARGUMENT FOR A MONETARY UNION
}

\author{
Charles van MARREWIJK* \\ Erasmus University Rotterdam, 3000 DR Rotterdam, The Netherlands \\ Casper G. de VRIES* \\ Catholic University of Leuven, B-3000 Leuven, Belgium
}

\begin{abstract}
If the real exchange rate follows approximately a random walk and in the presence of nontraded goods, a monetary union may generate a Pareto improvement. The argument is based on the analogy with the advantages that derive from the formation of a customs union. A novel unit roots test based on the arc sine law is advanced.
\end{abstract}

\section{Introduction}

Several arguments have been advanced in favor of the formation of a monetary union. These arguments rely on criteria such as sufficient factor mobility (Mundell), a high share of tradables (McKinnon), product diversification (Kenen), financial integration (Ingram), and similarity of inflation rates (Fleming), which are considered conditiones sine quibus non for reaping the benefits from monetary integration. The benefits supposedly derive from the returns to scale using the same currency and reduced international commodity price uncertainty. As for the costs of unification, the loss of autonomy over setting the inflation rate and collecting the seignorage is often mentioned. For a detailed review of the issues concerning monetary unions the interested reader is referred to Ishiyama (1975) and Allen and Kenen (1980).

Here we like to draw attention to a novel argument in favor of a monetary union in the sense of a single currency area. It is based on the customs union argument in combination with the empirical regularity that real exchange rates follow approximately a random walk. Even though research has not been able to turn up significant (negative) effects of short term exchange rate volatility on trade [cf. Hooper and Kohlhagen (1978), Gotur (1985) and Bailey et al. (1986)], it is widely recognized that the long term swings in, for

*We are grateful to Steven Brakman, Harris Dellas, Giancarlo Gandolfo, Kees Koedijk, Bert Scholtens and Jerome Stein for their highly insightful comments, and to Edith Siermann for her computational assistance. 
instance, the dollar-mark rate over the past two decades have exerted a substantial influence on the volume of trade. Short-term volatility effects are mitigated by the presence of forward markets [cf. Ethier (1973)]. Long-term movements in one direction or the other, however, cannot be hedged and therefore exert an influence which is comparable to a temporary change in the terms of trade. This is the analogue of the distorting price effect caused by a tariff. For example, Frenkel and Razin (1989) recently argued that pegged exchange rates are equivalent to a lump sum tax cum subsidy policy. In a world with trade distortions, there exists a well known argument [see Kemp and Wan (1976), Dixit and Norman (1986)], whereby a subset of countries may form a customs union that constitutes a Pareto improvement. In this paper we intend to make this line of argument precise for the potential advantages that derive from the formation of a monetary union if the real exchange rate approximately follows a random walk. The ncar random walk feature is tested for in a novel way on the basis of the arc sine law. The new test is insightful as it directly reveals how a random walk in exchange rates distorts relative prices.

\section{Monetary union}

In this section the analogy between exchange rate and tariff distortions is studied. To this end we consider two economies, one with a monetary distortion, the other with a pure trade distortion.

\subsection{Nontraded goods and the exchange rate}

Suppose preferences are of the Cobb-Douglas type. Let there be $n+1$ goods, $n \geqq 1$ of which are traded and of which the first good, that is indexed by $\mathrm{h}$, is nontraded. The budget shares of the traded goods are $\beta_{i}, i=1,2, \ldots, n$, $0<\beta_{i}<1$, and $\sum \beta_{i}<1$. The nontraded good's budget share is $\beta_{\mathrm{h}}=1-\sum \beta_{i}$. Prices of the traded goods are $P_{i}$ and the price of the nontraded good is $P_{\mathrm{h}}$. The true cost of living index $P$ with Cobb-Douglas preferences is $\Gamma$ see Deaton and Muellbauer (1980, p. 178)]

$$
P=P_{\mathrm{b}}^{\beta_{\mathrm{h}}} \prod_{i=1}^{n} P_{i}^{\beta_{i}},
$$

where the right-hand side of eq. (1) has been set equal to 1 in the base period.

A similar relation holds for the foreign country. For the traded goods we have, by the law of one price, $P_{i}^{*}=W P_{i}$, that is, zero transport costs, etc., where $W$ is the bilateral exchange rate (in units of foreign currency per unit 
of domestic currency), and the superscript * refers to the foreign country's variables. Hence, the foreign country's price index $P^{*}$ reads

$$
P^{*}=\left(P_{\mathrm{h}}^{*}\right)^{\beta_{\mathrm{h}}} \prod_{i=1}^{n}\left(W P_{i}\right)^{\beta_{i}}=W P\left(P_{\mathrm{h}}^{*} / W P_{\mathrm{h}}\right)^{\beta_{\mathrm{h}}}
$$

For the base period it is assumed that $P_{\mathrm{h}}^{*}=W P_{\mathrm{h}}$, which implies purchasing power parity (PPP) and $P^{*}=W P$. Upon taking logarithms of the above equation and using lower case letters to denote variables that are transformed into logarithms, we get

$$
p^{*}-p-w=\beta_{\mathrm{h}} z
$$

where $z=p_{\mathrm{h}}^{*}-p_{\mathrm{h}}-w$. Note that either $z=0$ or $\beta_{\mathrm{h}}=0$ implies PPP for the current period. Also note that $\beta_{\mathrm{b}}=z=0$ implies relative PPP, not necessarily absolute PPP [cf. Levich (1985, p. 984 and p. 1003)]. Absolute PPP is obtained when our assumptions about the base period are correct. While the above describes the demand side of the economy, it can be easily integrated in a full scale model of the economy with a supply side as well. For example, the Ricardian model of trade may serve this purpose as is evident from the exposition in Dornbusch et al. (1977) and Dornbusch (1980, ch. 8). Another possibility would be to consider variable factor supplies in combination with the Heckscher-Ohlin-Samuelson trade model [see Woodland (1982, ch. 8)]. In the Ricardian trade model deviations from PPP arise in conjuction with a distortion, like nominal wage rigidity which becomes effective once there is a disturbance in one of the two money supplies. In response to the money supply innovation the exchange rate adjusts to partially restore PPP. The adjustment is imperfect due to the presence of nontraded goods. Obviously, with a common shock to both money supplies, that is, as in the case of a monetary union, PPP is not lost.

\subsection{Traded goods and tariffs}

Consider the case where all goods are traded, that is, good $h$ is traded as well. Suppose that the foreign country imports this commodity $h$ on which it levies a specific tariff $(T-1)>0$. To distinguish the commodity prices under the current regime from the previous one, they are denoted by $Q_{i}$. The foreign price index becomes

$$
Q^{*}=W T^{\beta_{\mathrm{h}}} Q_{\mathrm{h}}^{\beta_{\mathrm{h}}} \prod_{i=1}^{N} Q_{i}^{\beta_{i}}
$$


which may be rewritten as

$$
q^{*}-q-w=\beta_{\mathrm{h}} \tau
$$

where $\tau=\log T$.

When the tariff rate $\tau$ is changed from zero to a positive number, it follows that there will be a deviation from PPP in the current period [cf. Dornbusch et al. $(1977$, p. 831$)]$.

\subsection{Equivalence}

Note the similarity of eqs. (3) and (5). In case $\beta_{\mathrm{h}}=0$, it is easily seen that $q=p$ and $q^{*}=p^{*}$, so that the two regimes become equivalent. Are there conditions under which the two regimes can be considered equivalent when $\beta_{\mathrm{h}}$ is positive? Suppose the tariff rate $\tau$ is stochastic instead of fixed, and equal in distribution to $z$. Let all tax revenues be rebuted to the same agents that profit from the movements in $w$. Moreover, all trade is in commodities, so that there are no capital movements. Under these conditions the two systems (3) and (5) are equal in distribution and can be considered to be equivalent [see also Frenkel and Razin (1989) who argue the same for a fixed rate regime].

In other words, the deviation from PPP in eq. (5) stems from a stochastic trade distortion, the deviation from PPP in eq. (3) derives from nominal exchange rate movements. With nontraded goods and stickyness in, say, nominal wages such that $\beta_{\mathrm{h}} \neq 00$ and $z \neq 0$, the movements in the nominal exchange rate caused by money supply changes impose an implicit tariff. The nominal exchange rate fluctuations thereby exert real effects, as they distort relative prices. For a transparent exposition on these real effects, see Dornbusch (1980, ch. 8). It pays to link this analogy with the stylized facts of exchange rates.

\section{The arc sine laws and potential benefits from a monetary union}

Several empirical studies document that real exchange rates follow approximately a random walk [see, e.g., Roll (1979), Frenkel (1981), Adler and Lehman (1983), Hakkio (1984), Frankel and Meese (1987)]. A similar observation holds for nominal exchange rates [see, e.g., Mussa (1979), Meese and Rogoff (1983)]. The random walk in nominal rates is almost undisputed, but for real rates the evidence is mixed. Huizinga (1987), Frankel and Meese (1987) and Koedijk and Schotman (1990), find significant mean reversion in real rates. These latter results are partly due to using more powerful tests, or derive from using longer samples. For example, Frankel and Meese (1987, pp. 124-125) cannot reject the random walk hypothesis on the basis of 
Dickey-Fuller $t$-statistics for data over the past decade, but do reject the hypothesis when using data over the past 116 years. In light of this evidence, the real rate is close to a random walk, but it may not have an autoregressive coefficient exactly equal to one. For practical purposes, such as modeling real-rate behavior over the medium term, however, the random walk in real rates may be a suitable working hypothesis. Consider, for example, the following stationary process:

$$
y(t)=\lambda y(t-1)+\varepsilon(t) .
$$

Here $\varepsilon(t)$ are i.i.d. innovations and $\lambda=1$ with probability $p=0.99$ and $0<\lambda<1$ with $p=0.01$. It is easily demonstrated that $90 \%$ of the histories are indistinguishable from a random walk for the time span $t=1,2, \ldots, 10$. In fact this is all we need to carry through our arguments. We chose to focus on the pure random walk process to expedite the presentation. Campbell and Clarida (1987), for example, also follow this methodology.

Suppose, then, that the real rate $r$ follows a. symmetric random walk, where $r=p^{*}-p-w$. Note, inter alia, that this implies that $p^{*}-p$ and $w$ cannot be cointegrated, given the observed random walk nature in the nominal rate $w$. At the same time, however, eq. (3) imposes that $r$ and $z$ are cointegrated. A sufficient condition for $r$ to follow a random walk is for instance that $p_{\mathrm{h}}^{*}-p_{\mathrm{h}}=0$ and that the nominal rate $w$ follows a random walk. Formally, the stochastic process $\{r(t)\}$ is defined as

$$
\begin{aligned}
& r(t)=r(t-1)+\varepsilon(t), \\
& r(0)=0, \\
& s(t)=r(t)-r(0)=\sum_{i=1}^{t} \varepsilon(i),
\end{aligned}
$$

where the zero boundary value indicates PPP at time zero, and $\varepsilon(t)$ are i.i.d. mean zero symmetric innovations. As is well known, 0 is a persistent state [see Feller (1970a, ch. XIV.7), Feller (1970b)]. Thus, with probability one $r(t)=s(t)=0$ for some future $t$. This amounts to an infinitely often recurrence to the PPP state. Being as it may be, deviations from PPP over prolonged periods of time are well documented [see, e.g., Isard (1977, p. 942), McKinnon (1979, p. 133), Levich (1985, pp. 1005-1006), Dornbusch (1986)]. It has puzzled many authors that short term deviations from PPP can be so large and persistent, even though long term PPP seems to hold [cf. Levich (1985, p. 989) and McKinnon (1979, p. 136)]. For this reason, according to Levich $(1985$, p. 1006), research has turned away from PPP to focus on 
Table 1

Discrete arc sine distribution."

\begin{tabular}{lllllll}
\hline $\begin{array}{l}\text { Percentage } x \text { of } \\
\text { time that } s(t)>0\end{array}$ & $x=0$ & $x-10$ & $x=20$ & $x=30$ & $x=40$ & \\
\hline Probability $L(x)$ & $x=100$ & $x=90$ & $x=80$ & $x=70$ & $x=60$ & $x=50$ \\
\hline
\end{tabular}

"Source: Feller (1970a).

explanatory models for these deviations. As it appears, however, these observations are exactly in line with the nature of the random walk in eqs. (6). It corresponds with predictions of the famous arc sine law [see Feller (1970a, ch. III.4, th. 2), Feller (1970b, ch. XII.8)].

Theorem 1 (Feller). Let $\varepsilon(t)$ and $r(t)$ be as defined under (6). The probability $L$ that $r(t)>0$ for $x \%$ of a discrete number of periods $k$, equals $L(x)=(k \pi)^{-1}$ $(x(1-x))^{-1 / 2}$. The distribution function of this density is $2 \pi^{-1} \arcsin \sqrt{x}$.

The remarkable feature of this theorem is that the probability of sojourn times is U-shaped. ${ }^{1}$ Table 1 adapted from Feller (1970a, p. 79) provides an example for $k=10$. The table indicates the low likelihood, that is, 0.0606 , of $r(t)$ being positive $50 \%$ of the time vis-à-vis the higher likelihood of $r(t)$ being positive (negative) for more than $50 \%$ of the time. The same distribution holds for the probability of the last time PPP occurred. Thus, it is far more likely that PPP occurred just recently or a long time ago, than that it lastly happened at half time. ${ }^{2}$ This explains why deviations from PPP are so persistent, because the real exchange rate is more likely to be overvalued or undervalued for a prolonged period of time than that it flip flops around the PPP value.

In order to scrutinize the empirical validity of the arc sine law, we constructed table 2 from the real exchange rates for 16 countries vis-à-vis the United States and Germany. For each bilateral rate 16 histories of eleven consecutive observations were formed from the total of 176 available monthly observations. For each history the first observtion was set apart and used as a reference point. We then simply counted how many times the other 10 observations exceeded the reference point. ${ }^{3}$ The frequency of these positive deviations is reported in table 2 as a fraction of the total number

\footnotetext{
${ }^{1}$ Theorem 1 also holds for certain continuous time random walks such as the Brownian motion.

${ }^{2}$ The U-shaped density imposes a nonlinearity upon the distribution function. It implies that the probability that for $x \%$ of the time or less $r(t)>0$ is concave-convex in $x$ (cf. the second part of Theorem 1 from which its name is derived).

${ }^{3}$ For each exchange-rate series we tested for symmetry as the arc sine law only applies to a symmetric random walk. On basis of the tests the Danish krone/German mark rate was excluded from the computations in table 2.
} 
Table 2

Frequency of the percentage of positive deviations from PPP."

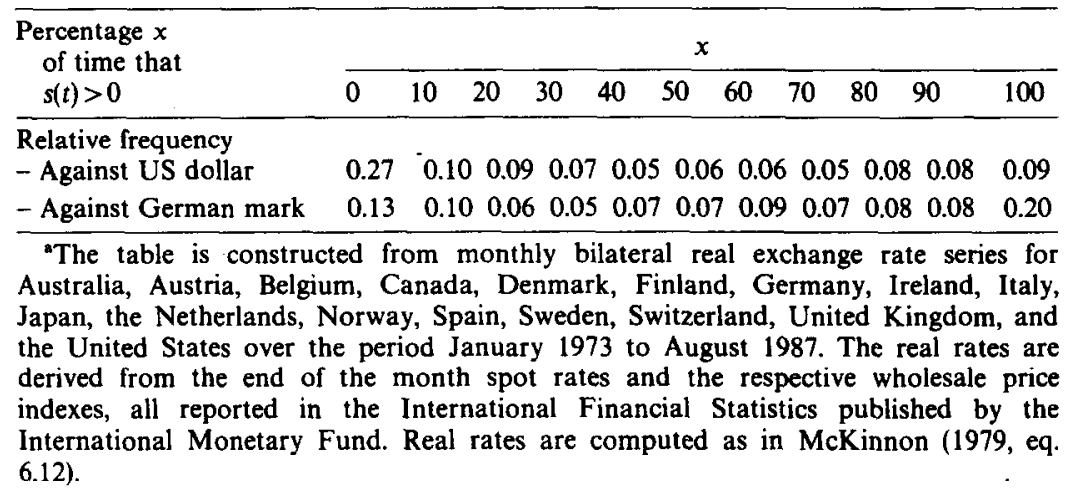

from the 256 and 240 histories for the dollar and mark rates, respectively. The U-shapedness is clearly present, though there is some asymmetry between the dollar and the mark rates. The near U-shapedness is confirmed by the chi-squared goodness of fit statistics $\chi^{2}(10)$ which are 25.6 and 8.8 for the real rates against the U.S. dollar and German mark, respectively. There are alternative tests against unit roots [see, e.g., Fuller (1976) and Cochrane (1988)]. To the best of our knowledge the current test is novel to the economics literature and is insightful as it directly reveals the persistence of the deviations from PPP.

Given the theoretical result which matches reasonably well with the empirical observations, there is a simple argument for the advantages derived from a monetary union. Above we established stochastic equivalence between eqs. (3) and (5). Therefore, the discussion may as well be cast in terms of a variable tariff $\tau(t)$. Formally, suppose that $\tau(t)$ follows a random walk such that $\tau(t)$ satisfies $(6)$. By theorem 1 this produces one way deviations from PPP for prolonged periods of time. Because every position $\tau$ attained by $\tau(t)$ can be considered as the origin of a new random walk with all the properties of the previous one, it is equally true that $\tau(t)>\tau$ for prolonged periods of time, ${ }^{4}$ where $\tau$ is a fixed positive number, say. Now invoke Kemp and Wan's (1976) theorem on customs unions.

Theorem 2 (Kemp-Wan). Consider any competitive world trading equilibrium with nonzero tariffs $\tau$. Let any subset of the countries form a customs union. Then there exists a common tariff vector and a system of lump-sum compen-

\footnotetext{
${ }^{4}$ In fact, the expected waiting time for the event $\tau(t)<\tau$ is infinite [see Feller (1970b, p. 395)].
} 
sations, involving only members of the union, such that there is an associated tariff-ridden competitive equilibrium in which each individual is not worse off. ${ }^{5}$

Kemp and Wan's result relates to fixed tariff rates $\tau$. With a symmetric random walk in tariff rates the argument applies as well, since $E[\tau(t+n)]=\tau$ for all positive $n$ when at time $t: \tau(t)=\tau$, and assuming risk neutrality (see also footnote 4). Given the equivalence between eqs. (3) and (5), we obtain the following proposition.

Proposition 1. When the real exchange rates follow a symmetric random walk, any subset of countries may benefit and nobody lose if those countries form a monetary union by instituting a single currency, revalue their common currency against the other currencies appropriately such that the trade with the rest of the world is as before, and compensate internally by lump-sum transfers. ${ }^{6}$

Proposition 1 applies to any subset of countries, but it is of interest to note that most monetary unions, like the EMS, involve multilateral agreements instead of bilateral, such as the monetary union between Belgium and Luxembourg. This has an empirical and theoretical basis. To evaluate the gains from bilateral versus multilateral agreements, compare the time series for a number of real bilateral exchange rates. For example, with the appropriate interpretation, the figure for several real effective exchange rates in Levich (1985) may be used. For convenience, this figure is reproduced as fig. 1. From such series it is immediate that while some rates do return to specific values, like the initial (PPP?) value, it is a coincidence when two rates return to this value simultaneously; while a simultaneous return of all rates is such a rare event that it is not observed in the samples. Thus multilateral PPP is much less likely to occur than bilateral PPP. In fact, the following theoretical result applies [see Feller (1970a, p. 360)].

Theorem 3 (Polya). There is probability one that a single or two independent discrete random walks simultaneously return to their initial positions. The probability that three or more random walks simultaneously return to their initial positions is less than one.

In a world with at least four different currencies, there are at least three independent real exchange rates. Assume that these latter rates all follow random walks. In the above we have interpreted long run PPP as the

\footnotetext{
${ }^{5}$ Dixit and Norman (1986) have shown that commodity taxes may be used instead of lump sum transfers. This scheme may be potentially easier to institute.

${ }^{\circ}$ The following caveat applies. Proposition 1 does not apply if there are other distortions, which is the second best problem. To advance possible confusion, note that in Section 2 the nominal wages are fixed such that PPP holds initially, i.e., the world is at the Pareto frontier.
} 

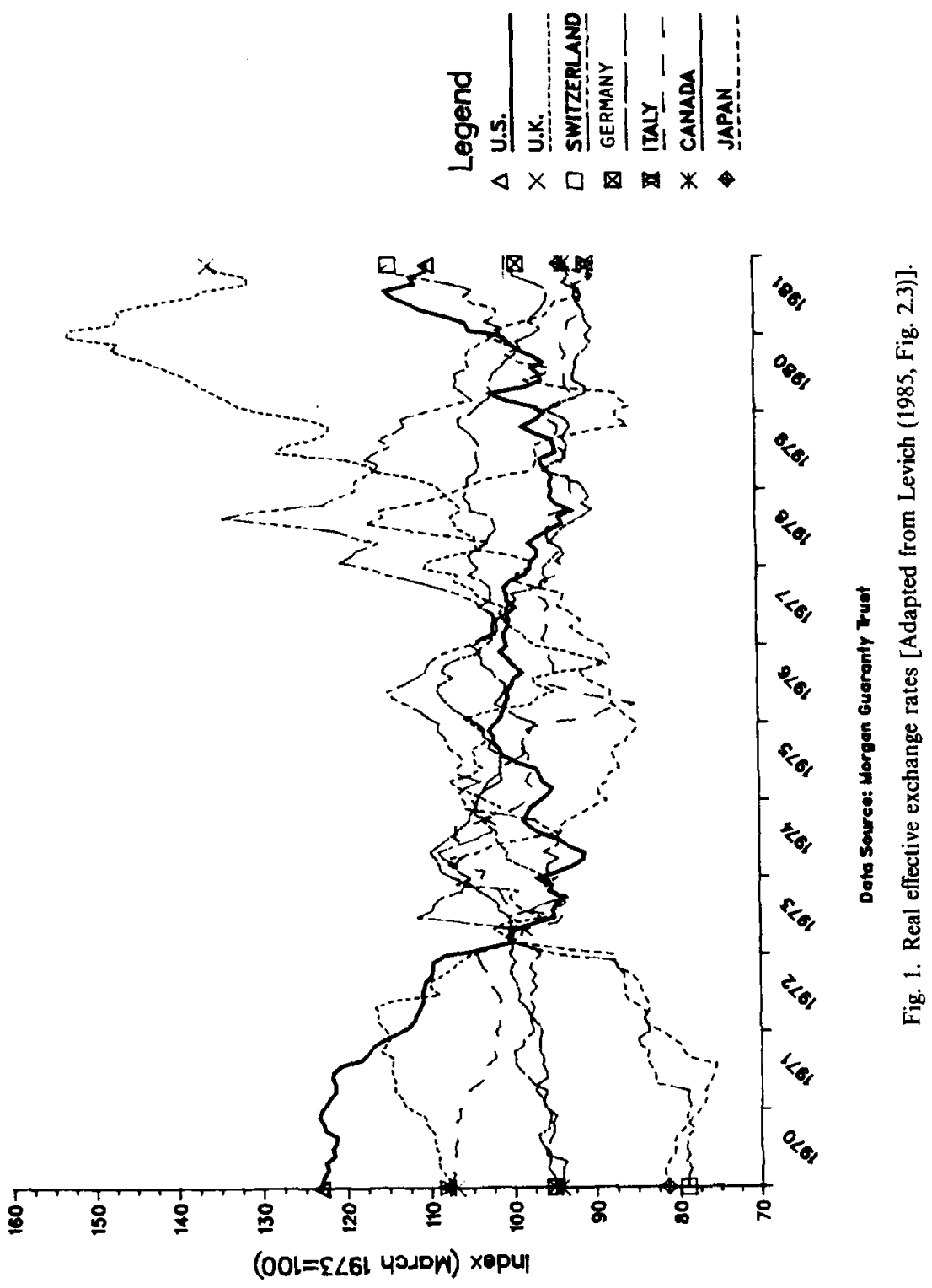
eventual and certain return to the initial position. In this sense, Theorem 3 implies that multilateral PPP for more than three countries is improbable, as a simultaneous return is uncertain. It is in this sense that the returns from multilateral monetary unions exceed the benefits from the sum of bilateral unions.

\section{References}

Adler, M. and B. Lehman, 1983, Deviations from purchasing power parity in the long run, Journal of Finance 39, 1471-1487.

Allen, P.B. and P.B. Kenen, 1980, Asset markets exchange rates and economic integration (Cambridge University Press, Cambridge, UK).

Bailey, M.J., G.S. Tavlas and M. Ulan, 1986, Exchange rate variability and trade performance: Evidence for the big seven countries, Weltwirtschaftliches Archiv 3, 466-477.

Campbell, J.Y, and R.H. Clarida, 1987, The dollar and real interest rates, Carnegie-Rochester Conference Series on Public Policy 27, 103-140.

Cochrane, J.H., 1988, How big is the random walk in GNP?, Journal of Political Economy 96, 893-920.

Deaton, A. and J. Muellbauer, 1980, Economics and consumer behavior (Cambridge University Press, Cambridge, UK).

Dixit, A. and V. Norman, 1986, Gains from trade without lump-sum compensation, Journal of International Economics 21, 111-122.

Dornbusch, R., 1986, Dollars, debts and deficits (MIT Press, Cambridge, MA).

Dornbusch, R., 1980, Open economy macroeconomics (Basic Books, UK).

Dornbusch, R., S. Fischer and P. Samuelson, 1977, Comparative advantage, trade and payments in a Ricardian model with a continuum of goods, American Economic Review 67, 823-839.

Ethier, W., 1973, International trade and the forward exchange market, American Economic Review 63, 494-503.

Feller, W., 1970a, An introduction to probability theory and its applications, Vol. I (Wiley, New York).

Feller, W., 1970b, An introduction to probability theory and its applications, Vol. II (Wiley, New York).

Frankel, J.A. and R. Meese, 1987, Are exchange rates excessively variable?, in: S. Fischer, ed., NBER macro economics annual (MIT Press, Cambridge, MA) 117-162.

Frenkel, J., 1981, The collapse of purchasing power parity during the 1970s, European Economic Review 16, 145-165.

Frenkel, J.A. and A. Razin, 1989, Exchange-rate management viewed as tax policies, European Economic Review 33, 761-782.

Fuller, W.A., 1976, An introduction to statistical time series (Wiley, New York).

Gotur, P., 1985, Effects of exchange rate volatility on trade, IMF Staff Papers 32, 475-512.

Hakkio, C., 1984, A re-examination of purchasing power parity: A multi-country and multiperiod study, Journal of International Economics 17, 265-278.

Hooper, P. and S.W. Kohlhagen, 1978, The effect of exchange rate uncertainty on the prices and volume of international trade, Journal of International Economics 8, 483-511.

Huizinga, J., 1987, An empirical investigation of the long-run behavior of real exchange rates, Carnegie-Rochester Conference Series on Public Policy 27, 149-214.

Isard, P., 1977, How far can we push the law of one price?, American Economic Review 67, 942-948.

Ishiyama, Y., 1975, The theory of optimum currency areas: A survey, Staff Papers (IMF, New York) 344-383.

Kemp, M.C. and H.Y. Wan, Jr., 1976, An elementary proposition concerning the formation of customs unions, Journal of International Economics 6, 95-97.

Koedijk, K. and P. Schotman, 1990, How to beat the random walk: An empirical model of real exchange rates, Journal of International Economics, forthcoming. 
Levich, R.M., 1985, Empirical studies of exchange rates: Price behavior, rate determination and market efficiency, in: R.W. Jones and P.B. Kenen, eds., Handbook of International Economics, Vol. II (North-Holland, Amsterdam) 979-1040.

McKinnon, R.I., 1979, Money in international exchange (Oxford University Press, New York).

Meese, R. and K. Rogoff, 1983, Empirical exchange rate models of the seventies: Do they fit out of sample?, Journal of International Economics 14, 3-24.

Mussa, M., 1979, Empirical regularities in the behavior of exchange rates and theories of the foreign exchange market, Carnegie-Rochester Series on Public Policy 11, 9-57.

Roll, R., 1979, Violations of purchasing power parity and their implications for efficient international commodity markets, in: M. Sarnat and G. Szegö, eds., International trade and finance, Vol 1 (Ballinger, Cambridge, MA).

Woodland, A.D., 1982, International trade and resource allocation (North-Holland, Amsterdam). 